\title{
The Effect of ISO 14001 Environmental Management System Implementation on SMEs Performance: An Empirical Study in Malaysia
}

\author{
Goh Yen Nee (Corresponding author) \\ Graduate School of Business, Universiti Sains Malaysia, 11800, Penang, Malaysia \\ E-mail: gohyennee@gmail.com \\ Nabsiah Abdul Wahid \\ Graduate School of Business, Universiti Sains Malaysia, 11800, Penang, Malaysia \\ E-mail: nabsiah@usm.my
}

\begin{abstract}
Despite the growing interest in examining ISO 14001 Environmental Management System (EMS) implementation and firm's performance, little attention has been devoted especially among the Small and Medium Enterprises (SMEs) in Malaysia. Based upon 61 responses questionnaire survey, this study examines the relationship of ISO 14001 EMS implementation to Malaysian SMEs performances. The findings of this study confirm that ISO 14001 EMS implementation has a positive and significant relationship with SMEs's performance. This finding is consistent with the environmental management literature mostly published in the developed countries. This study is important as the empirical results provide an indicator to encourage other SMEs which has no EMS in place to consider joining the bandwagon. Since the ISO 14001 standard is still on a voluntary basis in Malaysia, this study able to give empirical evidence on SMEs performance appears to be critical at this juncture noting the fact that SMEs contributes to the largest business establishments in Malaysia.
\end{abstract}

Keywords: ISO 14001, Environmental Management System, Small and Medium Size Enterprises (SMEs), Malaysia

\section{Introduction}

Over the years, worldwide concern for the environment has been gaining much attention. Industrial activities which lead to environmental pollution has raise the concern on promoting more environmentally friendly production in order to mitigate the impacts of pollution. Further, it has been reported that a significant amount of commercial and industrial waste were from the industrial activities of SMEs. SMEs represent majority of the businesses in Malaysia. Based on the Malaysian SMEs Annual Report (2008), SMEs constitutes 99.2\% of total business establishment and forms about $56 \%$ of the total workforce. Based on the definitions determined by the Malaysian SME Corporation, an enterprise can be considered an SME in each of the respective sector was based on the Annual Sales Turnover or Number of Full-Time Employees. For services, primary agriculture and information \& communication technology (ICT), a small and medium enterprise is an enterprise with full-time employees not exceeding 50 or annual sales turnover not exceeding RM5 million. For manufacturing, manufacturing-related services and agro based industries, a small and medium enterprise is an enterprise with full-time employees not exceeding 150 or with annual sales turnover not exceeding RM25 million.

ISO14001 EMS refers to an organization's management system (i.e. set of interrelated elements used to establish policy and objectives and to achieve those objectives which encompassed organizational structure, planning activities, responsibilities, practices, procedures, processes and resource) used to develop and implement its environmental policy and manage its environmental aspects" (MS ISO 14001: 2004, p.2) which adhere to the ISO 14001 standards. To date, empirical evidence has proven that ISO 14001 EMS bring significant improvement in firm's performance. Therefore, getting SMEs to attend to their daily operation and business performance with an ISO 14001 EMS in place are critical. For instance, empirical evidence has reported that SMEs commitment towards environmental improvement can lead to significant benefits in firm's performance. In addition, the benefits of ISO 14001 are widely acknowledged by authors such as Biondi et al. (2000) and Babakri et al. (2004). As up to date, only a total of 118 SMEs certified with ISO 14001 have been identified from the Federation of Malaysian Manufacturer (FMM) (2009) Directory and Malaysian Certified Online Databases (latest update until 31 August 2009). Therefore, it is crucial to find out what is the significant impact of ISO 14001 EMS implementation on firms' performance (i.e. operation and business performance) to further encourage other firms which has no ISO 14001 EMS in place to consider implementing it in the near future so that they are not losing their track to compete locally and globally. In light of this, the purpose of this study is to examine the impact of ISO 14001 EMS implementation on Malaysian SMEs performances (i.e. operation and business performance). 


\section{Literature Review}

\subsection{ISO14001 Environmental Management System (EMS) Implementation}

ISO 14001 standards on environmental management provide a system for tracking, managing and improving performance regarding the environmental requirements. Conformance to the ISO standard requires policy commitments to compliance with all regulatory requirements and other mandates such as pollution prevention and EMS continual improvement which can be verified by an external auditor (Gallagher et al., 2004). Based on the requirements of ISO 14001 standards as stated in the Handbook of Malaysian standard: Environmental Management System: Requirements with Guidance for Use, a firm must comply with all the elements in order to be qualifying for the certification which includes:

- General requirements;

- Environmental policy;

- Planning (i.e. environmental aspects, legal and other requirements, objectives and targets, environmental management programme);

- Implementation and operation (i.e. structure and responsibility, training, awareness and competence, communication, environmental management system, document control, operational control, emergency preparedness and response);

- Checking and corrective action (i.e. monitoring and measurement, non-conformance and corrective and preventive action, records and environmental management system audit) and Management review.

\subsection{SMEs' Performance}

Review of literature has identified a mixed of empirical evidence on the relationship between ISO 14001 EMS implementation and firm's performance. For instance, empirical studied by Biondi et al.(2000) found out that EMS implementation in SMEs will contributes to organizational and managerial efficiency, continuous monitoring of compliance and improvement of enterprise's image. Sambasivan and Ng (2008) have identified some perceived benefits from implementing ISO 14001 and it can be illustrate into four main factors (i.e. improved company reputation and image, increased staff morale and motivation, profit, performance and opportunity, customer loyalty and trust). In addition, Tan (2005) studied found out that the perceived benefits of implementing ISO 14001 include better business control, transparency/openness, marketing advantages, cost reduction, less injuries/environmental accidents, more research and development, improvement in operations efficiency, company's image improved and improved work culture. On the other hand, Babakri et al. (2004) through a survey conducted on a sample of certified industrial companies in United States reported that companies recycling performance is significantly affected by ISO14001 certification. Hence the size of the firms also has shown a significant influence where smaller firms experienced greater improvements in recycling performance compare to large firms (Babakri et al. 2004).

\subsection{Resource Based View (RBV)}

RBV argues that organizational capabilities are a source for competitive advantage (Voola et al. 2004). Thus, capabilities that are internal to a firm are the main reason for the differences in its profitability (Wernerfelt, 1984; Barney, 1991). ISO 14001 EMS implementation is an organization's management system which is unique for a firm as firms may group its own resources (i.e. physical, human and organizational) together to form its own capabilities that by itself can enhance the value of a resource and leads to competitive advantage. Therefore, ISO 14001 EMS implementation as a system are unique to SMEs as one of its organizational capabilities that can brings significant effects on its performance such as in operation and business performance.

\subsection{Research Framework and Proposed Hypotheses}

Based on the literature review and RBV as the underpinning theory, the following hypotheses were developed from the framework in Figure 1. They are:

Hypothesis: ISO 14001 EMS implementation has a positive and significant relationship with Malaysian SMEs performance.

Hypothesis a: ISO 14001 EMS implementation has a positive and significant relationship with Malaysian SMEs operation performance.

Hypothesis b: ISO 14001 EMS implementation has a positive and significant relationship with Malaysian SMEs business performance.

\section{Methodology}

\subsection{Sample and Procedure}

The focus of the study is at the firm level and the unit of analysis will be the individual SME. In the study, the authors defined SMEs as an enterprise with full-time employees not exceeding 150. Based on this definition, a total of 118 SMEs certified with ISO 14001 have been identified from the Federation of Malaysian Manufacturer (FMM) (2009) Directory and Malaysian Certified Online Databases (latest update until 31 August 2009). Due to 
the small population, the entire population will be used as the sample. This study will use census as a method to obtain information from all the 118 SMEs certified with ISO 14001. Data were collected using a structured questionnaire. The questionnaire was first validated through a pre-test administered to various ISO consultant, academics and managers from SMEs. The pre-test subjects point out that the content of each hypothesis was well represented by the measurements items employed for the study.

Then, the survey questionnaire will be send through mail and/or email attachment. An email was sent to firms that provide email addresses as part of their profiles in the directory and databases and printed survey questionnaires with returned postage affixed was sent to the rest of the firms. The survey will be sent to the firms upon the name of the contact person stated in the directory list and databases. The distribution of questionnaires to actual respondents was based on the judgment of the contact person. He or she must assure that the questionnaire should be completed by the most senior person responsible for the environmental management function in their respective firms. Clear instructions were given to contact person to ensure that the individual selected as respondents must be those involved with the ISO 14001 Environmental Management System (EMS) in their respective firms, specifically the environmental management representative (EMR).

\subsection{Measurement}

As for variables and measurement, this study was carried out using a structured questionnaires survey and the selection of measurements items was based on exhaustive review of literature, in-depth and details evaluations by the authors and the practicing managers plus the ISO consultant. This method is deemed to be sufficient in obtaining the relevant data to examine the purpose of this study. The dependent variable, Malaysian SMEs performance was measured in two dimensions namely operation and business in fourteen items which were derived from Montabon et al. (2000). Meanwhile, the independent variable, ISO 14001 EMS implementation was measured using eight items adapted from Lefebvre et al. (2003). All responses were measured using five-point Likert type scale with scale ranging from "strongly disagree" (1) to "strongly agree" (5). In addition , two control variables are apply namely experiences with other ISO certification and firm size in which previous empirical research showed a significant relationship with firm's performance.

As for data analysis, statistical software analysis package SPSS version 16 was used for all major statistical analysis. Questionnaire responses were codified and entered into the database. Descriptive, reliability analysis and multiple regression analysis technique appropriate for examining the purpose of this study was proposed for this study.

\section{Findings}

\subsection{Response Rate}

A total of 118 questionnaires were mailed to the respondents. With a close follow up by telephone call, email, first reminder letter and personally meet up with the respondent to hand in the questionnaires, 61 completed questionnaires was received. The usable response rate is $51.7 \%$. The response rate is deemed to be exceptionally good as responses expected from mail survey are usually low (Sekaran, 2003). This may due to the small incentive enclosed together with the mail questionnaire which intends to improve the response rate of mail questionnaire. In addition, a close follows up by arranging meeting with the respondents to hand in the questionnaire personally also helping a lot in improving the response rate. The response rate is also considered to be good when comparing to other similar studies from previous research. For instance, Tan (2005) conducted study on ISO 14001 firms in Malaysia which give a 47.4\% of response rate. On the other hand, Samat et al. (2006) conducted their study among service organizational in the northern region of Malaysia also achieved a response rate of $57.71 \%$ which is significantly higher than the standard $20 \%$ acceptable mail survey response rates.

\subsection{Validity and Reliability of Measurement Scales}

Table 1 shows the results of validity and reliability analyses for measurement scales. Factor analysis with varimax rotation was carried out for the independent variable and dependent variable. Basically, the factor analysis with varimax rotation condensed the dependent variable, namely firm's performance into two dimensions, i.e. operation and business with 3 items left respectively ( 8 items with factor loadings less than 0.70 were omitted). As for the independent variable, the 7 items of ISO 14001 EMS implementation were loaded cleanly on one factor ( 1 item with factor loadings less than 0.70 were omitted). This study use factor loadings of 0.70 as cut-off point based on the sample size of 61 as suggested by Hair et al. (2006). All constructs showed eigenvalue larger than 1 , in which operation performance (3.61) with factor loadings in the range of 0.78 to 0.93 , business performance (1.40) with factor loadings in the range of 0.81 to 0.93 and ISO 14001 EMS implementation (5.33) with factor loadings in the range of 0.76 to 0.94 . The KMO score for operation performance is 0.76 , business performance is 0.76 and ISO 14001 EMS implementation is 0.86 . The Cronbach's Alpha reliabilities for each construct are operation performance (0.87), business performance (0.91) and ISO 14001 EMS implementation (0.94). These statistical analyses confirm that the measurement scales have measure the same constructs and met the acceptable standards based on the guidelines defined by Hair et al. (2006). 
Table 2 shows the results of mean, standard deviation and Pearson correlation analyses. The means for dependent and independent variable are from 3.69 to 4.55 signifying that the levels of operation performance, business performance and ISO 14001 EMS implementation ranging from above average high (3) to highest level (5). As for the correlation coefficients between the independent and dependent were less than 0.90 indicating that the data has no serious collinearity problem (Hair et al., 2006).

\subsection{Regression Analysis Hypotheses Testing}

In order to test the hypotheses, multiple regression analyses were conducted to determine the variance of firm's performance explained by ISO 14001 EMS implementation. From factor analysis, firm's performance was found as two factors that measured through two ways, namely operation performance and business performance. The results are summarized in Table 3.Table 3 presents the multiple regression results of control variables (experience with other ISO certification and firm size) and firm's performance (i.e. operation and business). In Table 3, for Model 1 in the $1^{\text {st }}$ dimension of firm's performance (operation), the control variable (experience with other ISO certification) has no significant influence on $1^{\text {st }}$ dimension of firm's performance (operation) except size $(\beta=-.26, \mathrm{p}<.10)$. In addition, both of the control variables in Model 1 explain only 7 per cent of the variance $(.07 \times 100)$ in the $1^{\text {st }}$ dimension of firm's performance (operation). For Model 2, the relational variables (include control variables) cumulatively contributed 18 per cent $(.18 \times 100)$ of the variance in $1^{\text {st }}$ dimension of firm's performance (operation). This value implies that 18 per cent of the variance in the $1^{\text {st }}$ dimension of firm's performance (operation) can be explained by the predictor variables. The results showed that ISO 14001 EMS implementation $(\beta=.34, \mathrm{p}<.01)$, was found positively and significantly associated with $1^{\text {st }}$ dimension of firm's performance (operation).

In Table 3, for Model 1 in the $2^{\text {nd }}$ dimension of firm's performance (business), both of the control variables have no significant influence on $2^{\text {nd }}$ dimension of firm's performance (business). In addition, both of the control variables in Model 1 explain only 4 per cent of the variance $(.04 \times 100)$ in the $2^{\text {nd }}$ dimension of firm's performance (business). For Model 2, the relational variables (include control variables) cumulatively contributed 39 per cent $(.39 \times 100)$ of the variance in the $2^{\text {nd }}$ dimension of firm's performance (business). This value implies that 39 per cent of the variance in the $2^{\text {nd }}$ dimension of firm's performance (business) can be explained by the predictor variables. The results showed that ISO 14001 EMS implementation $(B=.60, p<.01)$, was found positively and significantly associated with $2^{\text {nd }}$ dimension of firm's performance (business). Therefore, the hypotheses of this study are fully supported.

\section{Conclusion}

In this study, it can be conclude that ISO 14001 EMS implementation has a positive and significant relationship with SMEs's performance (i.e. operation performance and business performance). These findings are distinctively important as it is solely based in Malaysia context which are different from previous study that focus mainly on developed countries. In addition, the findings will be very helpful where publicity and promotion regarding the positive significant effects towards firm's performance can be made available to all the SMEs, such as through the cooperation with Small and Medium Enterprise (SME) Corporation Malaysia, Federation of Malaysian Manufacturers (FMM) and Standard and Industrial Research Institute of Malaysia (SIRIM) Berhad to encourage other SMEs to join in the bandwagon. Lastly, it is recommended that the validated framework be replicated in other sector, industries or other countries with large sample size which would provide further validation and reinforcement to the framework from this study. ISO 14001 EMS implementation has been adopted by many industries in different countries. In Malaysia, the adoption can be identified typically in the manufacturing sector and some in service sector (i.e. hotel industry). It is recommended to extend the framework to other industry such as the education industry (e.g. public or private academic institutions).

\section{References}

Babakri, K. A.,Bennett, R.A., Rao, S., and Franchetti, W (2004). Recycling performance of firms before and after adoption of the ISO 14001 standard. Journal of Cleaner Production, 12, 633-637.

Barney, J. (1991). Firm resources and sustained competitive advantage. Journal of Management, 17(1), 99-120.

Biondi, F., Fey, M., \& Iraldo, F. (2000). Environmental management system and SMEs. Greener Management International, 29, 55-69.

Federation of Malaysian Manufacturer Directory (2009). $\left(40^{\text {th }}\right.$ ed). Federation of Malaysian Manufacturer (FMM).

Gallagher, D. R., Andrews, R. N .L., Chandracai, A \& Rohitratana, K. (2004). Environmental management system in US and Thailand. Greener Management International, 46, 41-56.

Hair, J. F., Black, W. C., Babin, B. J., Anderson, R. E. \& Tatham, R. L. (2006). Multivariate data analysis. $6^{\text {th }}$ edition, Upper Saddle River: Pearson Education International.

Hillary, R. (2004). Environmental management systems and the smaller enterprise. Journal of Cleaner Production, 12, 561-569. 
Lefebvre, E. Lefebvre, L. A. \& Talbot, S. (2003). Determinants and impacts of environmental performance in SMEs. $R$ \& D Management, 33(3), 263-283.

Montabon, F., Melnyk, S. A. Sroufe, R. Calantone, R. J. (2000). ISO 14000: Assessing it perceived impact on corporate performance. Journal of Supply Chain Management, 36(2), 4-16.

MS ISO 14001 (2004). Handbook of Malaysian standard: environmental management system: requirements with guidance for use (first revision), Department of Standards Malaysia.

National SME Development Council (2005). Definitions for small and medium enterprises in Malaysia, Retrieved August 19, 2009 from www.smeinfo.com.my/pdf/sme_definitions_ENGLISH.pdf.

Petroni, A. (2001). Developing a methodology for analysis of benefits and shortcomings of ISO 14001 registration: lesson from experience of a large machinery manufacturer. Journal of Cleaner Production, 9, 351-364.

Rahman, S. (2001). A comparative study of TQM practice and organizational performance of SMEs with and without ISO 9001 certification. International Journal of Quality and Reliability Management, 18(1), 35-49.

Samat, N. Ramayah, T. \& Mat Saad, N. (2006). TQM practices, service quality and market orientation: some empirical evidence from a developing country. Management Research News, 29(11), 713-728.

Sambasivan, M. \& Ng, Y. F. (2008). Evaluation of critical success factors of implementation of ISO 14001 using analytic hierarchy process (AHP): a case study from Malaysia. Journal of Cleaner Production, 16, $1424-1433$.

Sammalisto, K. \& Brorson, T. (2008). Training and communication in the implementation of environmental management system (ISO 14001): a case study at the University of Gävle, Sweden. Journal of Cleaner Production, 16, 299-309.

Sekaran, U. (2003). Research methods for business: a skill building approach $\left(4^{\text {th }}\right.$ ed). New York: John Wiley and Sons.

SME Annual Report (2008). Overview of SMI/SMEs, Retrieved August 19, 2009 fromhttp://www.smibusinessdirectory.com.my/aboutsmisme/allaboutsmisme/306overview-of mis/smes.

SME Corporation (2009). Definitions of SMEs, SME Corp Malaysia, Retrieved August, 17, 2009 from http://www.smidec.gov.my/node/33.

Sohail, M. S. \& Hoong, T.B. (2003). TQM practices and organizational performances of SMEs in Malaysia. Benchmarking, 10(1), 37-53.

Sroufe, R. (2003). Effects of environmental management system on environmental management and practices and operations. Production and Operation Management, 12(3), 416-431.

Tan, L. P. (2005). Implementing ISO 14001: is it beneficial for firms in newly industrialized Malaysia? Journal of Cleaner Production, 13, 397-404.

Terziovski, M., Power, D. and Sohal, A. M. (2003). The longitudinal effects of ISO 9000 certification process on business performance. European Journal of Operational Research, 146, 580-595.

Toshiyuki, B. \& Takehiro, T. (2006). Current status and features of ISO 14001 certification in Universities of Japan. Science Bulletin, 61(1), 7-23.

Voola, R., Carlson, J. \& West, A. (2004). Emotional intelligence and competitive advantage: examining the relationship from a resource-based view. Strategic Change, 13(2), 83-93.

Wernerfelt, B. (1984). A resource based view of the firm. Strategic Management Journal, 5, 171-180.

Zeng, S.X., Tian, P. and Tam, C.M. (2007). Overcoming barriers to sustainable implementation of the ISO 9000 system. Managerial Auditing Journal, 22(3), 244-254.

Table 1. Validity and Reliability of Analyses for Measurement Scales

\begin{tabular}{ccccccc}
\hline Measure & Items & Factor Loadings & KMO & Eigenvalue & $\begin{array}{c}\text { Variance } \\
\text { Explained }\end{array}$ & $\begin{array}{c}\text { Cronbach's } \\
\text { Alpha }\end{array}$ \\
\hline $\begin{array}{c}\text { Operation } \\
\text { Performance } \\
\text { Business }\end{array}$ & 3 & $0.78-0.93$ & 0.76 & 3.61 & 60.17 & 0.87 \\
$\begin{array}{c}\text { Performance } \\
\text { ISO 14001 EMS } \\
\text { implementation }\end{array}$ & 7 & $0.76-0.94$ & 0.86 & 5.33 & 76.20 & 0.94 \\
\hline
\end{tabular}


Table 2. Descriptive Statistics and Pearson Correlation Analyses

\begin{tabular}{|c|c|c|c|c|c|c|}
\hline \multirow[t]{2}{*}{ Variables } & \multirow[t]{2}{*}{ Mean } & \multirow{2}{*}{$\begin{array}{l}\text { Standard } \\
\text { Deviation }\end{array}$} & \multicolumn{4}{|c|}{ Pearson Correlation Analysis } \\
\hline & & & 1 & 2 & 3 & 4 \\
\hline $\begin{array}{l}\text { ISO } 14001 \text { EMS } \\
\text { implementation }\end{array}$ & 4.55 & 0.55 & .11 & 1 & & \\
\hline Operation & 3.69 & 0.71 & .08 & $.30^{* *}$ & 1 & \\
\hline Performance & & & & & & \\
\hline $\begin{array}{c}\text { Business } \\
\text { Performance }\end{array}$ & 4.27 & 0.57 & .01 & $.57^{* *}$ & $.46^{* *}$ & 1 \\
\hline
\end{tabular}

Note: ${ }^{* *} \mathrm{p}<.01$

Table 3. Result of Multiple Regression Analysis

Dependent Variable:

Firm's Performance

\begin{tabular}{|c|c|c|c|c|}
\hline & \multirow{2}{*}{\multicolumn{2}{|c|}{ Operation }} & & \\
\hline & & & \multicolumn{2}{|c|}{ Business } \\
\hline & Model 1 & Model 2 & Model 1 & Model 2 \\
\hline \multicolumn{5}{|l|}{ Control Variable: } \\
\hline $\begin{array}{l}\text { Experience with other ISO certification } \\
(\mathrm{Yes}=1, \mathrm{No}=0)\end{array}$ & -.18 & $-.23^{*}$ & -.13 & $-.22^{*}$ \\
\hline Firm Size $($ Small $=1$, Medium 0$)$ & $-.26^{*}$ & $-.28^{* *}$ & -.18 & $-.21^{*}$ \\
\hline \multicolumn{5}{|l|}{ Independent Variable: } \\
\hline EMS & & $.34^{* * *}$ & & $.60^{* * *}$ \\
\hline $\mathrm{R}^{2}$ & .07 & .18 & .04 & .39 \\
\hline Adjusted $\mathrm{R}^{2}$ & .04 & .14 & .00 & .36 \\
\hline $\mathrm{R}^{2}$ Change & .07 & .11 & .04 & .35 \\
\hline Significance F Change & .11 & .01 & .35 & .00 \\
\hline F Value & 2.274 & $4.27^{* * *}$ & 1.07 & $12.06^{* * *}$ \\
\hline Durbin-Watson & \multicolumn{2}{|c|}{1.87} & \multicolumn{2}{|c|}{2.11} \\
\hline
\end{tabular}

Notes: ${ }^{* * *} \mathrm{p}<0.01 ;{ }^{* *} \mathrm{p}<0.05 ;{ }^{*} \mathrm{p}<0.10$

\section{Appendix}

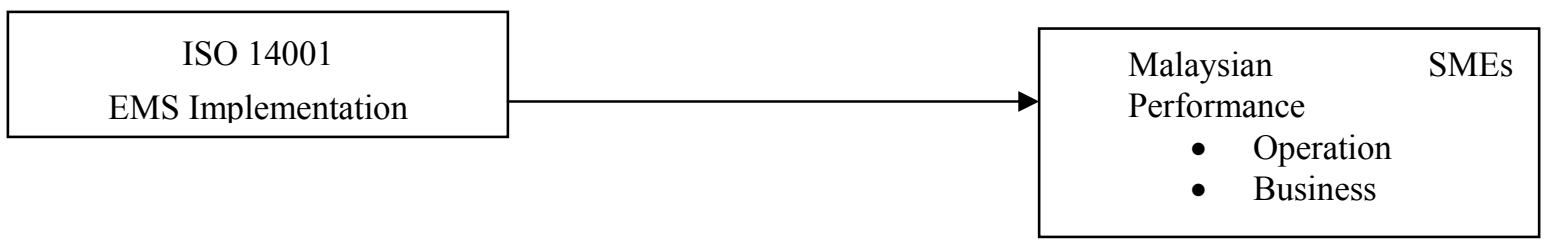

Figure 1. Research Framework 